\title{
Arterial endothelium creates a permissive niche for expansion of human cord blood hematopoietic stem and progenitor cells
}

Huilin $\mathrm{Li}^{1 \dagger}$, Haiyun Pei ${ }^{2,3^{*}+}$, Sihan Wang ${ }^{1,3}$, Bowen Zhang ${ }^{2,3}$, Zeng Fan', Yiming Liu ${ }^{1,3}$, Xiaoyan Xie ${ }^{1,3}$, Zhou Yang ${ }^{1}$, Lei Xu1, Yali Jia ${ }^{2,3}$, Yun Bai ${ }^{1}$, Yi Han ${ }^{3}$, Lin Chen ${ }^{1,3}$, Lijuan He $\mathrm{He}^{1,3}$, Xue Nan ${ }^{1,3}$, Wen Yue $\mathrm{e}^{1,3^{*}}$ and Xuetao Pei ${ }^{1,3^{*}}$

\begin{abstract}
Background: Although cord blood (CB) offers promise for treatment of patients with high-risk hematological malignancies and immune disorders, the limited numbers of hematopoietic stem cell (HSC)/progenitor cell in a CB unit and straitened circumstances in expanding ex vivo make it quite challenging to develop the successful cell therapies.

Methods: In this study, a novel strategy has been developed to support ex vivo expansion of hematopoietic stem and progenitor cells (HSPCs) by coculture with engineered human umbilical arterial endothelial cells (HuAECs-E4orf1-GFP), which expresses E4ORF1 stably by using a retroviral system.

Results: Coculture of CD34 ${ }^{+}$hCB cells with HuAECs-E4orf1-GFP resulted in generation of considerably more total nucleated cells, $\mathrm{CD} 34^{+} \mathrm{CD} 38^{-}$, and $\mathrm{CD} 34^{+} \mathrm{CD} 38^{-} \mathrm{CD} 90^{+} \mathrm{HSPCs}$ in comparison with that of cytokines alone or that of coculture with human umbilical vein endothelial cells (HuVECs) after 14-day amplification. The in vitro multilineage differentiation potential and in vivo repopulating capacity of the expanded hematopoietic cells cocultured with HuAECsE4orf1-GFP were also markedly enhanced compared with the other two control groups. DLL4, a major determinant of arterial endothelial cell (EC) identity, was associated with CD34 ${ }^{+}$hCB cells amplified on HuAECs-E4orf1-GFP.

Conclusions: Collectively, we demonstrated that HuAECs acted as a permissive niche in facilitating expansion of HSPCS. Our study further implicated that the crucial factors and related pathways presented in HuAECs may give a hint to maintain self-renewal of bona fide HSCs.
\end{abstract}

Keywords: Arterial endothelial cells, Hematopoietic stem and progenitor cells, Expansion, Niche, Transplantation

\section{Introduction}

Hematopoietic stem cells (HSCs), resided at the apex of a complicated blood cellular hierarchy, can replenish themselves by self-renewal and give rise to all the other blood cells [1]. Currently, generation of HSCs from

\footnotetext{
*Correspondence: peihy@hotmail.com; yuewen0206@126.com; peixt@nic.bmi.ac.cn

${ }^{\dagger}$ Huilin Li and Haiyun Pei are co-first authors

2Experimental Hematology and Biochemistry Lab, Beijing Institute of Radiation Medicine, Beijing 100850, China

${ }^{1}$ Stem Cell and Regenerative Medicine Lab, Institute of Health Service and Transfusion Medicine, Beijing 100850, China

Full list of author information is available at the end of the article
}

pluripotent stem cells (PSC), including induced pluripotent stem cells (iPSC) and embryonic stem cells (ESC), is probably out of reach [2-4]. And bone marrow (BM), umbilical cord blood (UCB), or mobilized peripheral blood (MPB) is the only source of HSCs presently available [5-7]. Consequently, establishing a system for ex vivo expansion of HSCs would open a unique opportunity to study human HSC self-renewal and provide a novel source of therapeutic cells for blood disorders. Achieving this goal requires a detailed understanding of crucial elements contributing to HSC amplification and function maintenance in hematopoietic niche in vivo. 
Umbilical cord actually contains a number of mostly naïve HSCs until delivery [8]. However, the cellular basis of the niche contributing to HSC maintenance in the umbilical cord is not yet clearly elucidated. As for anatomic structure, apart from vascular smooth muscle cells and perivascular mesenchyme, hematopoietic cells are in close vicinity of endothelial cells (ECs). In fact, during mammalian embryogenesis, endothelial and hematopoietic cells develop in parallel [9]. Recent reports suggested that HSCs derive from hemogenic endothelial cells lining the aortic floor both in murine and zebrafish [10, 11]. Consistently, definitive hematopoiesis cannot occur in the absence of endothelial cell development and arterial specification in the embryo [12]. This research collectively indicated that the appearance of cells having definitive HSC characteristics is in close association with arterial endothelium. Notably, umbilical arteries have been identified by a number of investigators as one of the primary birthplace of HSCs except the dorsal aorta in the aorta-gonad-mesonephros (AGM) region and the vitelline arteries [13, 14], raising the possibility that arterial endothelial cells (AECs) within umbilical cord might harbor a complex network of signals to modulate the nascent HSCs. Interestingly, there is growing evidence that endothelium not only plays a fundamental role in the generation of definitive HSCs but also is essential for the self-renewal of HSCs in vitro or BM repopulation in vivo recently $[15,16]$. These observations raise the question of whether AECs within the umbilical cord are also one of the niche components for HSC amplification and function maintenance. To investigate this possibility, we thus presumably speculated that an ex vivo human umbilical arterial endothelial cell (HuAEC) vascular niche would provide intrinsic regulators contributing to the expansion of HSCs.

Primary AECs have limited expansion capability and undergo de-differentiation in culture [17, 18], making physiologic application as hematopoiesis niche challenging. On this account, here we developed stable HuAEC lines possessed the conventional characteristics of AECs by transduction of E4ORF1 and the green fluorescent protein (GFP) using retrovirus vectors (HuAECs-E4orf1GFP). These based on the theory of E4orf1 as a "pro-life" signal to promote survival of primary endothelial cells (PECs) $[19,20]$. Then we revealed that HuAECs-E4orf1GFP have potentiality to create a permissive niche for expansion of $\mathrm{hCB} \mathrm{CD} 34^{+}$cells, as determined by a conventionally defined set of markers for human hematopoietic stem and progenitor cells (HSPCs), colony assays, and in vivo repopulating capacity in NOD.Cg-Prkdc ${ }^{\text {sci- }}$ ${ }^{\mathrm{d}} \mathrm{Il} 2 \mathrm{rg}^{\mathrm{tm} 1 \mathrm{Wjl}} / \mathrm{SzJ}$ (NSG) mice. Furthermore, we found that Notch signaling molecules contribute to the supportive effect of HuAECs-E4orf1-GFP. Our data show, for the first time, a functional link between HuAECs and HSC amplification and indicate the potential role of arterial vascular niche to decode the in vivo information for self-renewal and expansion of human HSCs.

\section{Materials and methods \\ Isolation and culture of umbilical cord arterial/vein endothelial cells}

The umbilical cord was collected by the Beijing Yuhe Chinese and Western Medicine Integrative Rehabilitation Hospital (ZXYEC-KT-2017-04-P01). Primary HuAECs and human umbilical vein endothelial cells (HuVECs) were isolated as previously described [21, 22]. A sterile technique was utilized in all manipulations of the cord. The cord was separated from the placenta soon after birth and stored in a sterile container filled with DMEM (Gibco, Big island, NY, USA) at $4{ }^{\circ} \mathrm{C}$ until processing. Storage time averaged about $2 \mathrm{~h}$, and cords were discarded if held more than $6 \mathrm{~h}$. Briefly, the umbilical cord arteries and vein were dissociated out and rapidly placed in preheated phosphate buffer saline (PBS; Gibco, Big island, NY, USA), and a 20$\mathrm{cm}$ clipping of the tissue was used for cell isolation. The arteries and vein were perfused with PBS to wash out the blood and allowed to drain. The one end of the umbilical arteries/vein was then cannulated with a syringe clamped shut with a hemostat. Then the arteries and vein were infused with Collagenase IV $(1 \mathrm{mg} / \mathrm{ml}$; Sigma-Aldrich, Shanghai, China) for $15 \mathrm{~min}$ of incubation at $37^{\circ} \mathrm{C}$ after the other end of blood vessel was secured with a hemostat. After incubation, the collagenase solution containing the ECs was flushed from the cord by perfusion with PBS in a sterile $50-\mathrm{ml}$ conical centrifuge tube and centrifuged at $1000 \mathrm{rpm}$ for $5 \mathrm{~min}$. Subsequently, the cell pellets were resuspended in EGM-2 medium (Lonza, Beijing, China) and incubated at $37^{\circ} \mathrm{C}$ under $5 \% \mathrm{CO}_{2}$. The cells were fed twice a week with a complete change of fresh culture medium. The umbilical cord samples used to isolate PECs were from several donors. The primary HuAECs and HuVECs from the same donor were paired for independent experiments.

\section{Virus preparation and transfection}

HuAECs-E4orf1-GFP and engineered human umbilical vein endothelial cells [20] (HuVECs-E4orf1-GFP) were generated by introducing a retroviral vector into primary HuAECs and HuVECs. Retrovirus was generated by transfecting MSCV-N E4ORF1 (Addgene, Shanghai, China; species, human adenovirus 5; size, $384 \mathrm{bp}$ plus $8162 \mathrm{bp}$; vector type, mammalian expression, retroviral; selectable markers, puromycin) and pMX-GFP (provided by Dr. Hiroyuki Hirai, USA) in Plat A cells using Lipofectamine 2000 (Invitrogen, Carlsbad, California, USA). Retroviral constructs were collected 44 and $68 \mathrm{~h}$ posttransfection. E4ORF1-transfected ECs were selected with $0.5 \mu \mathrm{g} / \mathrm{ml}$ puromycin (InvivoGen, Shanghai, China). The DLL4 shRNA and control shRNA (both carry GFP label) 
were designed by Genechem (Shanghai, China) and transfected individually into primary HuAECs. Transfected $\mathrm{GFP}^{+}$cells were enriched via fluorescenceactivated cell sorting (FACS) Verse flow cytometer (BD Biosciences, Franklin, NJ, USA). Virus transfection experiments were performed on PECs from three different donors.

\section{Flow cytometry (FCM)}

Flow cytometric analysis was performed using the following antibodies: CD144-PE, CD45-APC, CD133-PE, CD31-APC, and CD309-PE for primary HuAECs and HuVECs; FVS510, CD34-PE, CD38-APC, and CD90-PEcy7 for ex vivo cultured assays; and anti-human CD45APC, CD19-APC, CD11b-PerCP-CY5.5, and anti-mouse CD45.1-FITC for in vivo transplantation experiments. Cells were stained at $4{ }^{\circ} \mathrm{C}$ for $40 \mathrm{~min}$, light protected. The filtered $(70 \mu \mathrm{m})$ samples were analyzed on the FACSVerse flow cytometer. All antibodies are from BD Biosciences (Franklin, NJ, USA) or eBioscience (San Diego, CA, USA).

\section{Immunofluorescence}

Primary HuAECs and HuVECs were stained for confirmation of cell identity. The cultures were fixed in $4 \%$ paraformaldehyde (Sigma-Aldrich, Shanghai, China), permeabilized and blocked, and then incubated overnight in blocking solution containing primary antibody against von Willebrand Factor (vWF; 1:500; Sino Biological, Beijing, China). FITC-conjugated Goat anti-rabbit IgG (1:200; Beijing Zhongshan Jinqiao Biological Technology, Beijing, China) was used as a secondary antibody and DAPI $(1 \mathrm{mg} / \mathrm{mL}$; Roche, Basel, Switzerland) as a nuclei counterstain. Imaging was performed using confocal microscopy (PerkinElmer, Waltham, MA, USA) and Volocity Software (PerkinElmer, Waltham, MA, USA).

\section{Tube formation assay}

Based on previously described [23], the primary HuAECs and HuVECs suspended in EGM-2 medium supplemented with VEGF $(100 \mathrm{ng} / \mathrm{ml}$; R\&D Systems, Aimolivel, California, CA, USA) were seeded into 6-well plates coated with Matrigel (BD Biosciences, Franklin, NJ, USA) prior at a density of 10,000 cells $/ \mathrm{cm}^{2}$. After $24 \mathrm{~h}$ of incubation, cells were photographed using confocal microscopy and Volocity Software.

\section{Quantitative real-time polymerase chain reaction (qRT- PCR) analysis}

Total RNA was extracted from cells by using RNeasy Micro Kit (QIAGEN, New York, NY, USA) and reverse transcribed by using ReverTra Ace qPCR RT Master Mix (TOYOBO, Shanghai, China) according to the manufacturer's specifications. The PCR products were detected using THUNDERBIRD SYBR qPCR Mix (TOYOBO, Shanghai, China). The primer sequences used in qRT-PCR assays are shown in Table 1.

\section{Nitric oxide production assay}

Based on the previous description [24], primary HuAECs and HuVECs were seeded into vitronectin-precoated 24well plates (100,000 cells/well). After 2 days, the cultured media were changed to fresh EGM-2 containing DAFFM $(1 \mu \mathrm{M}$; Life Technologies, Carlsbad, CA, USA). The cells were cultured for $30 \mathrm{~min}$ at $37^{\circ} \mathrm{C}$ and then harvested for flow cytometric analysis.

\section{Ex vivo coculture}

The sample of human $\mathrm{CB}$ was collected by the Beijing Yuhe Chinese and Western Medicine Integrative Rehabilitation Hospital (ZXYEC-KT-2017-04-P01). After density gradient centrifugation and immunomagnetic selection (Miltenyi Biotec, Westphalia, Gladbach, Germany), a total of 50,000 CD34 $4^{+}$cells were cultured in StemSpan (STEM CELL Technologies, Shanghai, China) containing $50 \mathrm{ng} /$ $\mathrm{mL}$ of rhSCF, rhTPO, and rhFlt-3 L (PeproTech, Rocky Hill, NJ, USA), with HuAECs-E4orf1-GFP and HuVECsE4orf1-GFP or without feeder cells (cytokines alone). Additionally, we also performed a Notch signaling blocking experiment in hCB cells cocultured with HuAECsE4orf1-GFP by adding Compound E $(200 \mathrm{nM}$; CpE; MERCK, Darmstadt, Germany), which is a Notch signal inhibitor. $\mathrm{CpE}$ was added every other day and an equivalent dose of DMSO was added as a control. In order to investigate the effect of DLL4 in the coculture system, the $\mathrm{CD}^{+}{ }^{+} \mathrm{hCB}$ cells were cocultured with HuAECs-E4orf1shDLL4 and its control group (HuAECs-E4orf1 carry unrecognized sequence and GFP). After 14 days, the expanded hCB cells were harvested for analyses.

\section{Colony-forming unit (CFU) assay}

For colony-forming assays, 250 amplified hCB cells were seeded into 24-well plates containing MethoCult H4434 (STEMCELL Technologies, Shanghai, China). Each group was performed in triplicate. The colonies including CFU-erythrocyte (CFU-E), burst-forming unit-erythroid (BFU-E), CFU-granulocyte (CFU-G), CFU-granulocyte, macrophage (CFU-GM), and CFU-megakaryocyte (CFU$\mathrm{M})$ emerged from day 7 and were scored on day 12 .

\section{Giemsa staining}

Colony-forming cells (CFCs) were assessed by means of the Giemsa staining kit (Baso, Zhuhai, China), according to the manufacturer's protocols. Equivolumetric cells were collected and distributed onto slides. Then, solution $\mathrm{A}$ was added and allowed to act for $1 \mathrm{~min}$ at room temperature. After that, solution B was added and 
Table 1 Quantitative RT-PCR primer sequences

\begin{tabular}{|c|c|}
\hline Gene & Sequence $\left(5^{\prime}-3^{\prime}\right)$ \\
\hline \multirow[t]{2}{*}{ CXCR4 } & F:GCCTTATCCTGCCTGGTATTGTC \\
\hline & R:GCGAAGAAAGCCAGGATGAGGAT \\
\hline \multirow[t]{2}{*}{ DLL1 } & F:GACGAACACTACTACGGAGAGG \\
\hline & R:AGCCAGGGTTGCACACTIT \\
\hline \multirow[t]{2}{*}{ DLL4 } & F:TGGGTCAGAACTGGTTATTGGA \\
\hline & R:GTCATTGCGCTTCTTGCACAG \\
\hline \multirow[t]{2}{*}{ EFNB2 } & F:TTCAGCCCTAACCTCTGGGG \\
\hline & R:CCTCCAAAGACCCATTTGATGTA \\
\hline \multirow[t]{2}{*}{ GJA4 } & F:TGCAAGAGTGTGCTAGAGGC \\
\hline & R:ACAAAGCAGTCCACGAGGTAG \\
\hline \multirow[t]{2}{*}{ HEY1 } & F:GTTCGGCTCTAGGTTCCATGT \\
\hline & R:CGTCGGCGCTTCTCAATTATTC \\
\hline \multirow[t]{2}{*}{ HEY2 } & F:CCTAACAGAAGTTGCGCGGTA \\
\hline & R:GAGGCGACAAGGGGTTGAC \\
\hline \multirow[t]{2}{*}{$J A G 1$} & F:GTCCATGCAGAACGTGAACG \\
\hline & R:GCGGGACTGATACTCCTTGA \\
\hline \multirow[t]{2}{*}{ NOTCH1 } & F:GAGGCGTGGCAGACTATGC \\
\hline & R:CTTGTACTCCGTCAGCGTGA \\
\hline \multirow[t]{2}{*}{$\mathrm{NOTCH} 2$} & F:CAACCGCAATGGAGGCTATG \\
\hline & R:GCGAAGGCACAATCATCAATGTT \\
\hline \multirow[t]{2}{*}{ NOTCH3 } & F:CGTGGCTACACTGGACCTC \\
\hline & R:AGATACAGGTGAACTGGCCTAT \\
\hline \multirow[t]{2}{*}{ NOTCH4 } & F:TGTGAACGTGATGTCAACGAG \\
\hline & R:ACAGTCTGGGCCTATGAAACC \\
\hline \multirow[t]{2}{*}{ APLNR } & F:CCTGCATCAGCTACGTCAACA \\
\hline & R:GGGATGGATTTCTCGTGCATCT \\
\hline \multirow[t]{2}{*}{ EPHB4 } & F:CGCACCTACGAAGTGTGTGA \\
\hline & R:GTCCGCATCGCTCTCATAGTA \\
\hline \multirow[t]{2}{*}{ NR2F2 } & F:AACCAGCCGACGAGATTCG \\
\hline & R:CCCGGATGAGGGTTTCGATG \\
\hline \multirow[t]{2}{*}{ NRP2 } & F:CCAACGGGACCATCGAATCTC \\
\hline & R:CCAGCCAATCGTACTTGCAGT \\
\hline \multirow[t]{2}{*}{ E4ORF1 } & F:CGCCGGAATTAGATCTGCCA \\
\hline & R:CTCGAGCAGCGTAATCTGGA \\
\hline \multirow[t]{2}{*}{ ANGPTL4 } & F:GGCTCAGTGGACTTCAACCG \\
\hline & R:CCGTGATGCTATGCACCTTCT \\
\hline \multirow[t]{2}{*}{ IGF2 } & F:GTGGCATCGTTGAGGAGTG \\
\hline & R:CACGTCCCTCTCGGACTTG \\
\hline \multirow[t]{2}{*}{ HOXB4 } & F:GCACGGTAAACCCCAATTA \\
\hline & R:GGCAACTTGTGGTCTITITT \\
\hline \multirow[t]{2}{*}{ GATA2 } & F:GCAACCCCTACTATGCCAACC \\
\hline & R:CAGTGGCGTCTTGGAGAAG \\
\hline \multirow[t]{2}{*}{ RUNX1 } & F:ATGTGGTCCTATTTAAGCCAGCCC \\
\hline & R:TCATCTGGCTGAAGACACCAGCTT \\
\hline
\end{tabular}

Table 1 Quantitative RT-PCR primer sequences (Continued)

\begin{tabular}{ll}
\hline Gene & Sequence (5'-3') \\
\hline HES1 & F:TCAACACGACACCGGATAAAC \\
& R:GCCGCGAGCTATCTTTCTTCA \\
GAPDH & F:GAGTCAACGGATTTGTCGT \\
& R:TTGATTTGGAGGGATCTCG \\
\hline
\end{tabular}

incubated for further $10 \mathrm{~min}$. Washed and air dried the samples before recording.

\section{In vivo transplantation}

All mice experiments were approved by the Institutional Animal Care and Use Committee (IACUC) at Institute of Health Service and Transfusion Medicine (Reference number: IACUC of AMMS-13-2016-016). Briefly, 6week-old NSG mice were sublethally total body irradiated (2.5 Gy) and injected 1,000,000 expanded hCB cells from each group through the tail vein intravenously. At 16 weeks, the peripheral blood (PB) cells/femurs/tibias/ spleens were collected and the percentage of human $\mathrm{CD} 45^{+}$cells was assessed.

\section{Statistical analysis}

Results are expressed as mean \pm standard deviation. $P$ value less than 0.05 (two-tailed Student's $t$ test) was considered statistically significant. The " $n$ " stands for biological replicates and all those repeats were independent.

\section{Results}

\section{Molecular and functional characterization of HuAECs}

Flow cytometric analysis was used to characterize cell surface markers on the subcultured HuAECs (Fig. 1a), showing that the HuAECs were positive for endothelial cell markers, such as CD31 and CD144, but negative for CD133 and CD45 (Fig. 1b), which suggested that the cells were free of endothelial progenitor cells $\left(\mathrm{CD} 133^{+}\right.$ cell population) or mature blood cells $\left(\mathrm{CD} 45^{+}\right.$cell population). HuVECs were also tested as controls. The expression of vWF, a common marker for human endothelium, was identified by immunofluorescence (Fig. 1c, Supplement Fig. 1a). In addition, tube formation assay was tested and the results showed that HuAECs plated in Matrigel can form capillary-like structures (Fig. 1d). qRT-PCR revealed that, compared with HuVECs, HuAECs expressed several arterial genes, including DLL4, EFNB2, and HEY2 [25], whereas the venous master regulators were greatly diminished, such as APLNR, EPHB4, NR2F2, and NRP2 [23] (Fig. 1e). To better understand their expression profile, we further analyzed the expression of another key AEC marker, KDR [26]. We found that HuAECs highly express KDR compared with HuVECs (Fig. 1f). We also performed analyses of arterial-specific functions, such as higher NO 


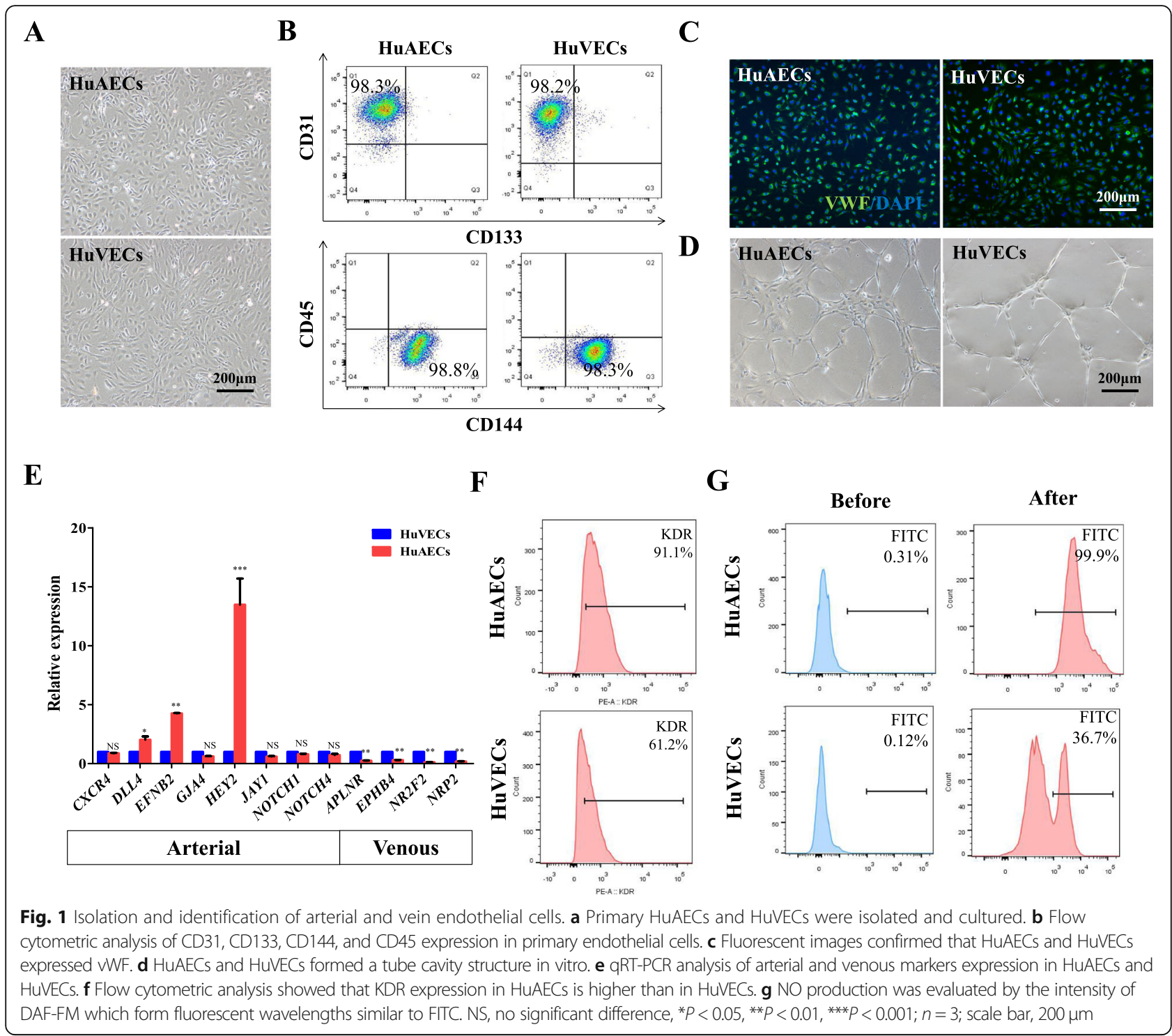

oxide production $[27,28]$, by comparing HuAECs with HuVECs. NO production was revealed by the intensity of DAF-FM. DAF-FM is nonfluorescent until it reacts with NO to form a fluorescent benzotriazole. The fluorescent intensity was measured by FCM and the results demonstrated that HuAECs produced higher NO than HuVECs (Fig. 1g).

\section{Establishment and identification of HuAECs-E4orf1-GFP feeders}

To test our hypothesis on the role of HuAECs in supporting ex vivo HSPC expansion, we isolated hCB $\mathrm{CD}^{+} 4^{+}$cells and cultured it in rhSCF, rhFlt3L, and rhTPO with or without feeder cells. The whole strategy is illustrated in Fig. 2a. The HuAECs-E4orf1-GFP were constructed by transduction of the HuAECs with the recombined retroviral vector MSCV-N E4ORF1 and pMX-
GFP. Then, the transgenic cell strains were further purified with $0.5 \mu \mathrm{g} / \mathrm{ml}$ puromycin selection for 3-5 days and FACS by GFP expression (Fig. 2b), with primary HuAECs as a control. HuAECs-E4orf1-GFP still maintain stable cell phenotype within 10 generations (Supplement Fig. 1B, C and D). To determine the expression of E4ORF1 in HuAECs-E4orf1-GFP, qRT-PCR was used to detect the expression level of E4orf1 mRNA in HuAECs-E4orf1-GFP or HuAECs. As shown in Fig. 2c, E4ORF1 was highly expressed in HuAECs-E4orf1-GFP feeders but barely in primary HuAECs. Briefly, HuAECs-E4orf1-GFP maintain the expression of arterial genes in serum/cytokine-free culture conditions (Fig. 2d). In contrast, primary HuAECs rapidly undergo apoptosis in serum/cytokine-free culture conditions (Supplementary Fig. 3A). On the other hand, primary HuAECs gradually decreased the AEC-specific gene expression with the increase of generations in the utilization of 


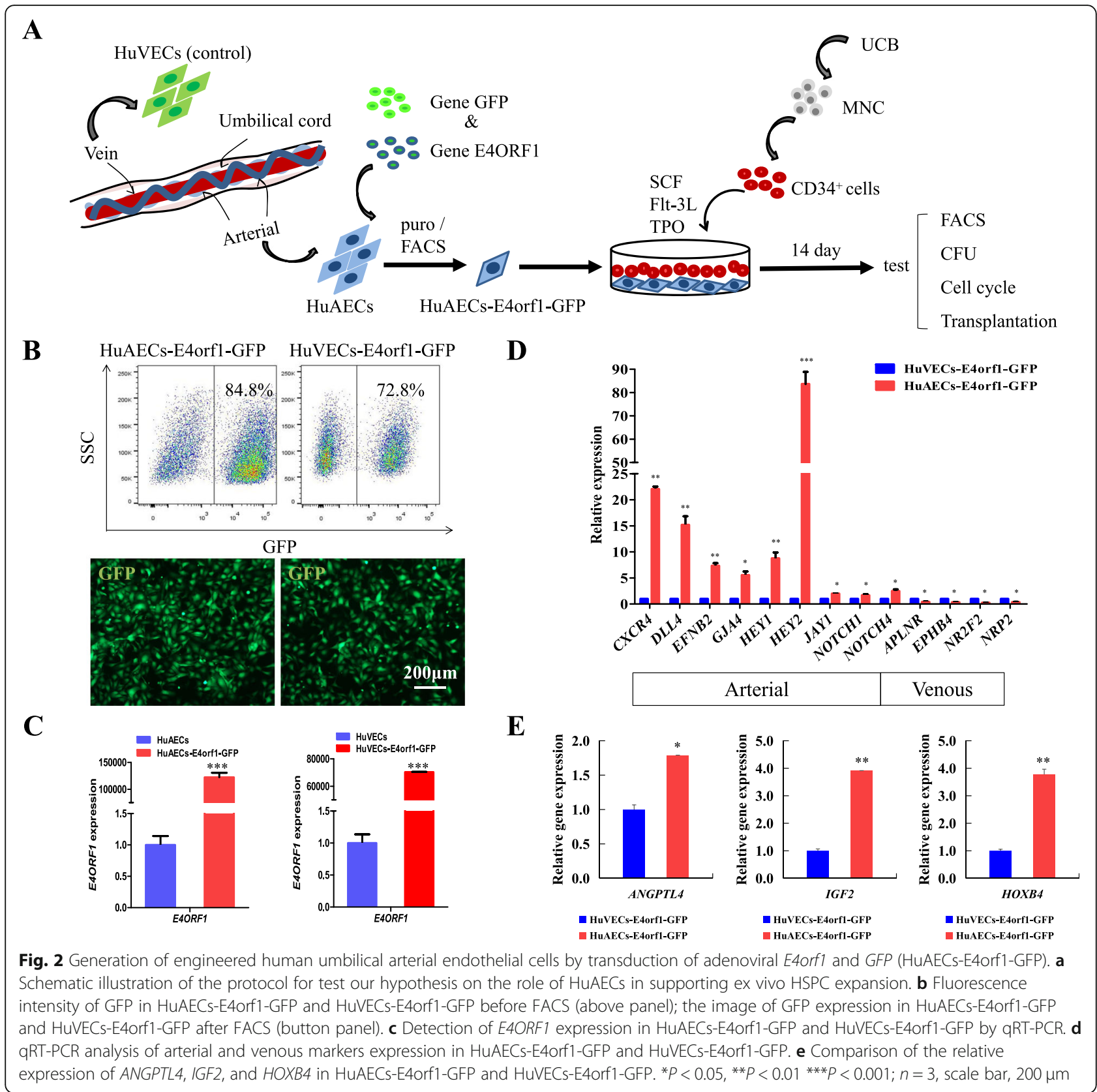

enriched EC growth medium supplemented with serum (Supplementary Fig. 3B). Besides, HuAECs-E4orf1-GFP expressed a higher level of growth factors and signaling molecules that support HSC expansion, including ANGP TL4 [29], IGF2 [30], and HOXB4 [31], compared with HuVECs-E4orf1-GFP (Fig. 2e).

\section{Coculture of HuAECs-E4orf1-GFP enhanced ex vivo expansion of CB HSPCs while heightened the} multilineage differentiation potential of HSPCs in vitro To test the effect of HuAECs-E4orf1-GFP on the ex vivo expansion of HSPCs, the $\mathrm{CD}_{3} 4^{+} \mathrm{hCB}$ cells were cumulatively expanded with HuAECs-E4orf1-GFP, HuVECs-E4orf1-GFP, or without feeders under serumfree and minimal cytokine conditions that incorporated rhSCF, rhTPO, and rhFlt3 as growth factors. The feeder cells used for coculture system were all within 6-10 passages. As a result, the $\mathrm{CD} 34^{+} \mathrm{hCB}$ cells cocultured with HuAECs-E4orf1-GFP resulted in significant augmentation of total nucleated cells (TNCs) and CD34 ${ }^{+}$cells than cytokines alone culture or HuVECs-E4orf1-GFP coculture (Fig. 3a-c). Moreover, the number of CD $34^{+} \mathrm{CD} 38^{-}$cells and more primitive $\mathrm{CD} 34^{+} \mathrm{CD} 38^{-} \mathrm{CD} 90^{+}$cells in expanded cells cocultured with HuAECs-E4orf1-GFP increased 


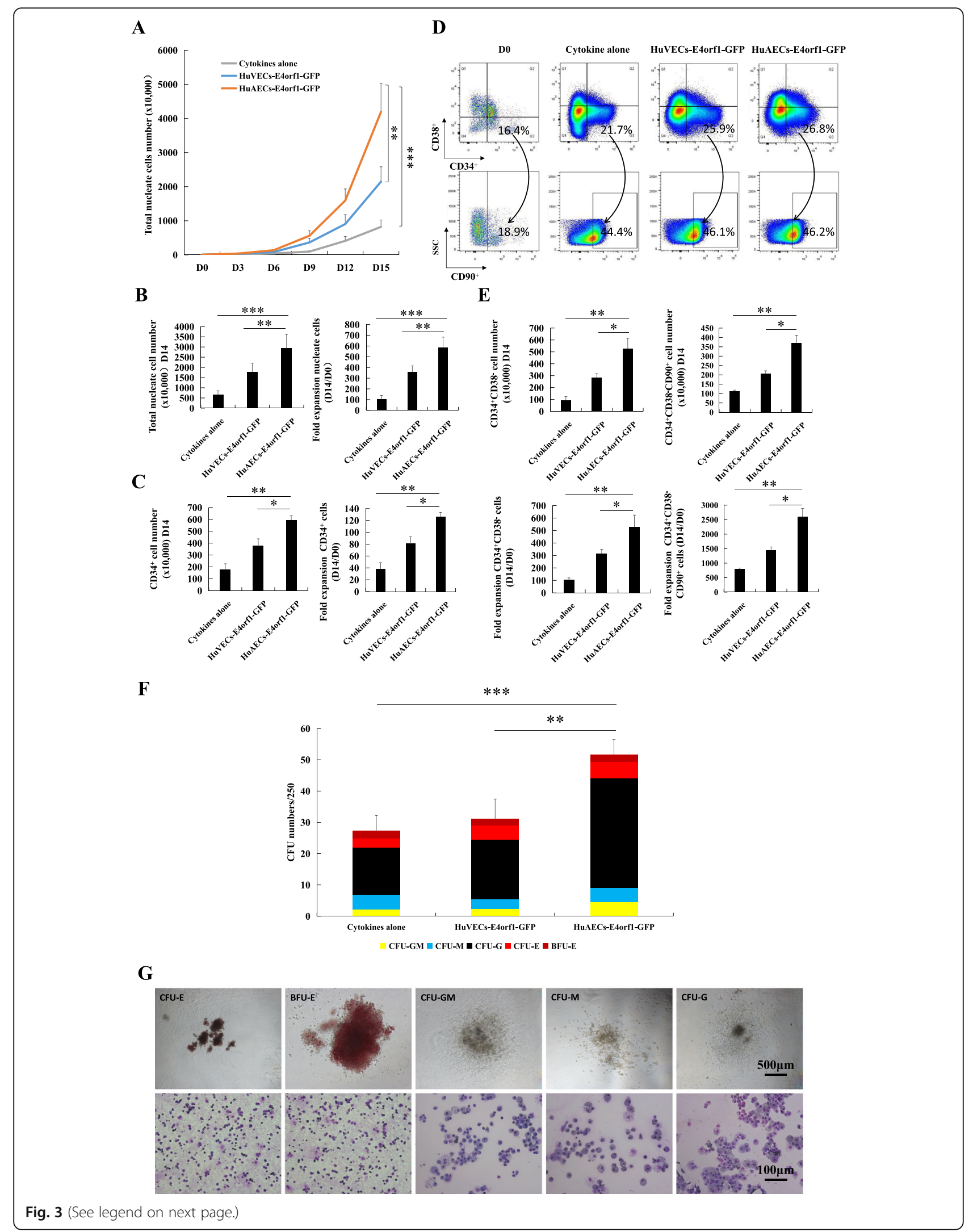


(See figure on previous page.)

Fig. $3 \mathrm{CD}_{34}{ }^{+} \mathrm{hCB}$ cells cocultured with HuAECs-E4orf1-GFP resulted in a significant expansion of HSPCs while heightened in vitro multilineage differentiation potential. a The cumulative curve of TNCs during the expansion. b TNC expansion. c Total CD34 ${ }^{+}$hematopoietic cell expansion. $\mathbf{d}$ Representative scatter plots of $\mathrm{CD} 34^{+} \mathrm{CD} 38^{-} \mathrm{CD} 90^{+}$cell expansion. e The number of $\mathrm{CD} 34^{+} \mathrm{CD} 38^{-}$cells (left panel) and $\mathrm{CD} 34^{+} \mathrm{CD} 38^{-} \mathrm{CD} 90^{+}$cells (right panel) significantly increased in the HuAECs-E4orf1-GFP group at day 14. f CFU numbers of amplified CD34 ${ }^{+}$hCB cells in different groups after 14-day expansion. g CFU (CFU-E, BFU-E, CFU-GM, CFU-M, and CFU-G) morphology (above panel, scale bar: $500 \mu$ m) and Giemsa's staining for cytospin samples of CFUs (bottom panel, scale bar: $100 \mu \mathrm{m}$ ). ${ }^{*} P<0.05$, ${ }^{* *} P<0.01,{ }^{*}{ }^{*} P<0.001 ; n=8$. Three HuAECs-E4orf1-GFP and HuVECs-E4orf1GFP cell lines were established and all of them have stable and consistent effects on ex vivo expansion of HSPCS

$527.2 \pm 96.3$ and $2603.4 \pm 283.2$-folds within 2 weeks, which was $6.6 \pm 2.5$ and $3.3 \pm 0.8$ times of the cytokines alone group, $1.9 \pm 0.5$ and $1.8 \pm 0.3$ times of the HuVECsE4orf1-GFP group (Fig. 3d, e). To assess the in vitro capability of multilineage differentiation in expanded CD34 $4^{+}$ hCB cells, CFU assay was performed. Compared with the other two groups, HuAECs-E4orf1-GFP coculture significantly increased numbers of CFU, demonstrating that the colony-forming potential of HSPCs was heightened in vitro in this condition (Fig. 3f, g).

\section{Expanded cells maintained repopulating activity in NSG mice in vivo}

In order to examine the hematopoietic reconstitution capacity in vivo, 1,000,000 progeny of ex vivo expanded $\mathrm{CD}_{4} 4^{+} \mathrm{hCB}$ cells from HuAECs-E4orf1-GFP coculture, HuVECs-E4orf1-GFP coculture or cytokine alone culture were transplanted into sublethally irradiated (2.5 Gy) NSG mice (Fig. 4a). Control mice were injected with PBS. Chimerism ratios were determined by flow cytometric analysis as the percentage of human $\mathrm{CD} 45^{+}$cells in $\mathrm{PB}, \mathrm{BM}$, and the spleen of NSG mice. Mice with more than $0.1 \%$ human cells were considered positive. We observed that the HuAECs-E4orf1-GFP-expanded group resulted in higher engraftment of human $\mathrm{CD}_{4} 5^{+}$cells than the HuVECs-E4orf1-GFP coculture or cytokine alone culture in $\mathrm{PB}$ after 4 weeks (frequency of engraftment, 4/8), 8 weeks (frequency of engraftment, 8/8), or 16 weeks (frequency of engraftment, 8/8) transplantation (Supplementary Fig. 4B). Furthermore, cocultured $\mathrm{CD}^{+} 4^{+}$hCB cells with HuAECs-E4orf1-GFP more efficiently engrafted human $\mathrm{CD}_{4} 5^{+}$cells at 16 weeks in mouse's spleen and BM after transplantation than that in $\mathrm{CD}_{34}{ }^{+} \mathrm{hCB}$ cells expanded with HuVECs-E4orf1-GFP or cytokines alone (Fig. 4b, c). These results show that HuAECs-E4orf1-GFP support the expansion of CD34 $4^{+}$ hCB cells which are capable of maintaining the longterm repopulating ability of NSG mice, while multilineage hematopoietic engraftment was also observed after 16-week transplantation (Supplementary Fig. 4A).

\section{Role of Notch signaling pathway in HSPC expansion}

DLL4 plays a critical role in activating the Notch pathway associated with proliferation and maturation of HSCs [32]. Interestingly, HuAECs-E4orf1-GFP express high levels of DLL4 compared to HuVECs-E4orf1-GFP. In view of this, we speculated that HuAECs-E4orf1-GFP might support ex vivo HSPC expansion through Notch signaling activation. For further verification, a specific Notch signaling inhibitor $(\mathrm{CpE})$ was used in our expansion system and the results showed that the growth-promoting activity of HuAECs-E4orf1-GFP on the expanded CD34 ${ }^{+}$ hCB cells was obviously hampered, reflected in TNCs, $\mathrm{CD}_{4}{ }^{+}, \mathrm{CD}_{3} 4^{+} \mathrm{CD} 38^{-}, \mathrm{CD} 34^{+} \mathrm{CD} 38^{-} \mathrm{CD}^{+} 0^{+}$cell, and even CFU numbers (Fig. 5a). Next, we further analyzed whether the reduced expression of DLL4 in HuAECs-E4orf1-GFP would affect HSPC expansion in coculture system. Simultaneously, an DLL4 knockdown coculture system was utilized to investigate the precise effects of DLL4 in HuAECs-E4orf1-GFP. HuAECs-E4orf1 were stably transfected with shDLL4 and negative control shRNA (Fig. 5b). qRT-PCR confirmed that DLL4 expression was effectively inhibited in HuAECs-E4orf1-shDLL4 (Fig. 5c). In this experiment, the suppression of cell proliferation and CFU formation was significantly greater in HuAECs-E4orf1shDLL4 coculture (Fig. 5d). Consistently, the CD34 ${ }^{+} \mathrm{hCB}$ cells amplified on HuAECs-E4orf1-GFP exhibited a higher level of Notch ligands, receptors, and target gene (GATA2, $H E S 1$, and RUNX1) transcription than cells with cytokines alone or HuVECs-E4orf1-GFP coculture on the 14th day of amplification (Supplementary Fig. 3C, D).

\section{Discussion}

Despite decades of efforts to explore the strategy of ex vivo HSC expansion, defining a set of cytokines that can expand long-term engraftable human HSCs has proven to be difficult so far [33]. The crux of this problem may lie in our ultimate incomprehension on the manipulation of HSCs by in vivo niche. Here we hypothesized HuAECs could act as a vascular niche to ex vivo expand HSPCs by providing prohematopoietic signals. To test this hypothesis, we established human umbilical cord arterial endothelial feeders by introducing the adenoviral E4ORF1 and GFP gene using a retrovirus vector. We took the lead in suggesting that HuAECsE4orf1-GFP provided a suitable cellular environment for effective expansion of $\mathrm{CD} 34^{+} \mathrm{hCB}$ cells with multipotency in vitro and engraftment capability in vivo.

In the present study, isolated HuAECs sustained in our cultures exhibited an AEC-surface expressional 


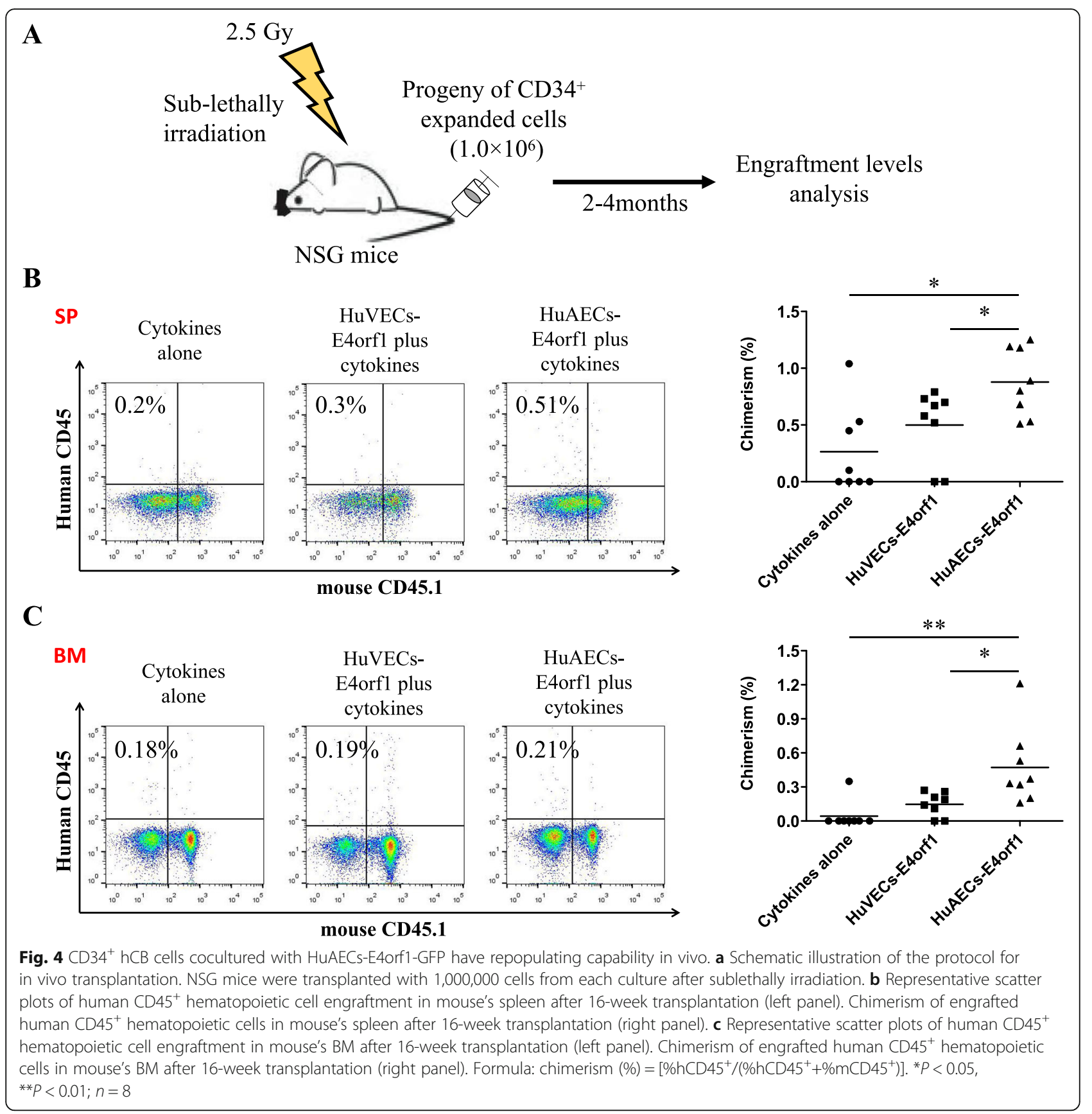

profile. Despite the well-known role for E4ORF1 in supporting long-term survival of primary endothelial cells in the absence of serum and angiogenic factors [34], this is the first report that E4ORF1 is directly involved in backing up the in vitro arterial identity. These studies make a case for retaining arterial genes and signaling, involving ligands DLL4 [35], receptors NOTCH1/4 [36], and transcription factors (TFs) HEY1/2 [25, 37] as a major determinant of AEC identity.
A requirement for complex signaling networks in ex vivo HSC expansion has motivated the development of cellular-based platforms. According to our current knowledge, mesenchymal stromal cells (MSCs) [38], osteoblasts [39], and other stromal cells, including sinusoidal cells and endothelial cells [40,41], are responsible for supporting hematopoiesis and controlling HSC numbers. Consequently, mesenchymal progenitor cells [42, 43] and endothelial cells [44, 45] have been widely used 


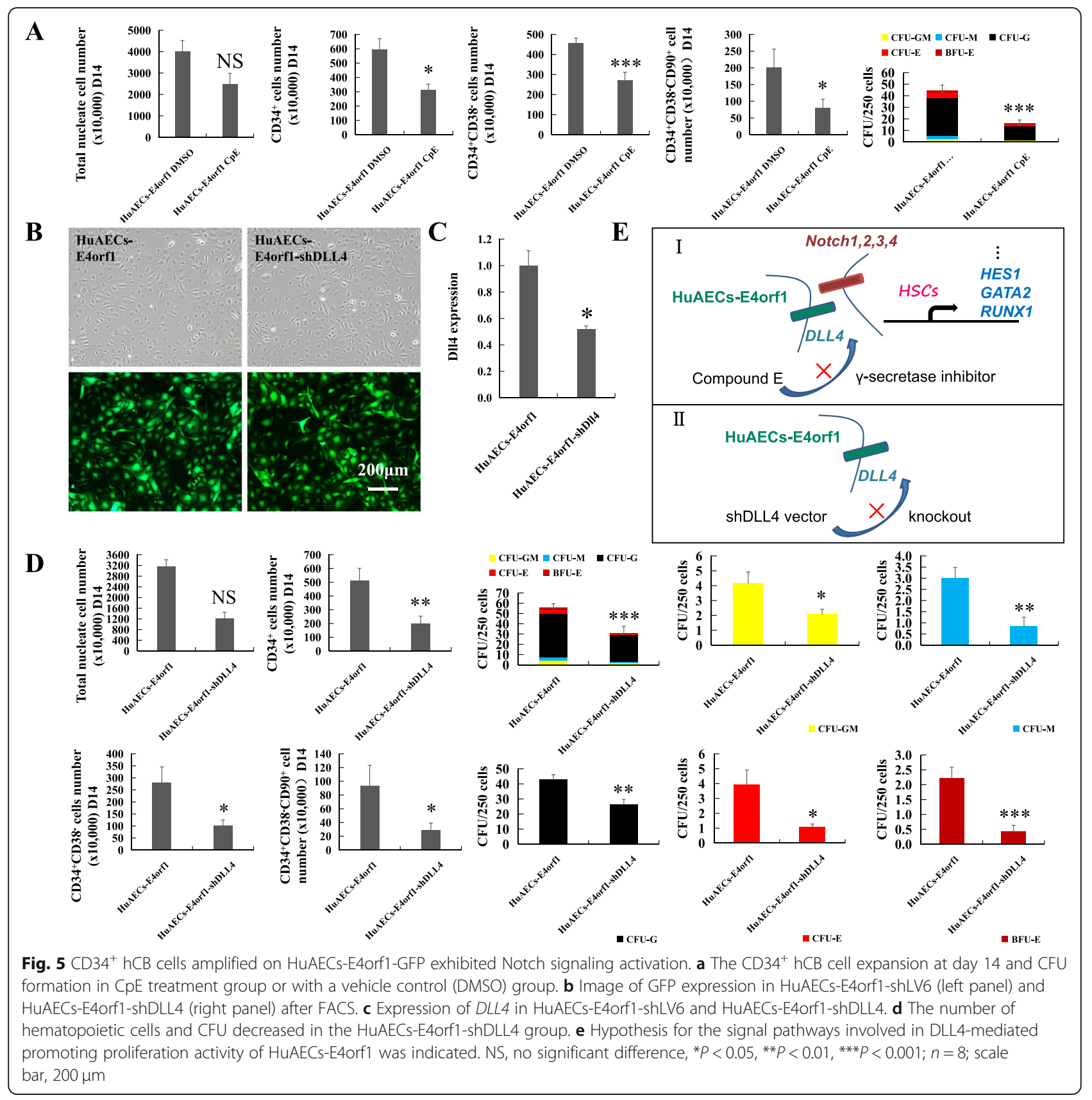

as surrogates for mesenchymal niche and endothelial niche to the expansion of HSPCs. Previously, we comprehensively characterized liver sinusoidal endothelial cells from the human fetal liver (hFLSECs) and found that they enable effective expansion of $\mathrm{CD} 34^{+} \mathrm{hCB}$ cells with multipotency in vitro and engraftment capability in NSG mice [46]. As we all know, the fetal liver serves as a predominant site for expansion of functional HSCs during embryogenesis [47], which makes much more sense about the important role of hFLSECs on the expansion of $\mathrm{CD} 34^{+} \mathrm{hCB}$ cells. In this study, we compared the capacity of hFLSECs and HuAECs to facilitate the expansion of CD34 ${ }^{+}$hCB cells. Encouragingly, HuAECs has the advantages over hFLSECs in growth-promoting activity and capability of CFU formation (Supplementary Fig. 2).

ECs lining arteries and veins have distinct molecular signatures and functions. Ligands $D L L 1 / 4$, receptors NOTCH1/4, and TFs $H E Y 1 / 2$ are major determinants of arterial EC identity [48-51]. As is well-known, hemogenic endothelium (HE) is associated with arteries. Former studies suggested that DLL4 $4^{\text {low/- }}$ cells within HE receive Notch-activating signals from DLL4 ${ }^{\text {high }}$ cells, sparking off an endothelial-to-hematopoietic transition 
[52]. Additionally, definitive hematopoiesis allied to endothelial cell development and arterial specification is regulated by the conserved signaling pathways Sonic Hedgehog, Wnt, and Notch, with a prominent role for the ligand DLL4 [35, 36, 53, 54]. In our study, we identified HuAECs-E4orf1-GFP expressed high levels of arterial genes, including DLL4, EFNB2, and HEY2 in comparison with HuVECs-E4orf1-GFP. Notably, the supplement of $\mathrm{CpE}$, a specific Notch signaling inhibitor, significantly hampered the growth-promoting activity of HuAECs-E4orf1-GFP. In view of the well-known role for DLL4 in arterial development, in vitro loss of function analyses were subsequently performed in HuAECsE4orf1-GFP. The results showed that knockdown of DLL4 remarkably decreased the proliferation and CFU formation of HSPCs in coculture system, implicating that DLL4 may be one of the candidate elements for supporting HSC expansion (Fig. 5e). These results may lay a foundation to further uncover the mechanisms of cross-talk between ECs and HSC during amplification.

Coculture of HSCs with stromal cells and growth factors has been utilized in an attempt to ex vivo recapitulate interactions in hematopoietic microenvironment to expand HSPCs. For instance, mesenchymal stromal cell (MSC)mediated expansion is one of the current approaches to the ex vivo manipulation of $\mathrm{CB}$ stem cells in clinical trials. Here we developed a new human CB expansion platform, and our study further confirmed the potential role for cell-based HSPC expansion methodologies. In our report, the primary HuAECs and HuVECs from the same donor were paired for independent experiments while the umbilical cord samples used to isolate PECs were from several donors. The different sources contained herein indicated that this coculture system is of universal applicability. In future, infusion of off-the-shelf HuAEC-mediated ex vivo expanded CB-derived HPSCs might be developed a novel strategy for dealing with the shortage of HSPCs. On the other hand, this platform might also allow identification of new growth factors or targeted defined molecules, contributing to define a set of cytokines for application in HSC expansion.

\section{Conclusion}

In summary, we identified that HuAECs acted as a potential cellular platform to efficiently support the expansion of engraftable human CB HSCs. Despite the wellknown role for endothelium in the initial generation of HSCs [55], HSC augment [56], and hematopoietic lineage-specific differentiation [52], this is the first time that arterial endothelial cells are directly involved in the ex vivo expansion of human HSCs. Ultimately, a better understanding of the cellular and signaling components in this region will advance the expansion of HSCs for therapeutic purposes.

\section{Supplementary information}

Supplementary information accompanies this paper at https://doi.org/10. 1186/s13287-020-01880-8.

\begin{abstract}
Additional file 1: Supplementary Fig. 1. The endothelial cell phenotype retained within 10 passages after transfection. (A) VWF staining negative control. (B) Flow cytometric analysis of CD31 and KDR expression in HuVECs-E4orf1-GFP. (C) Flow cytometric analysis of CD31 and KDR expression in HuAECs-E4orf1-GFP. (D) qRT-PCR analysis of arterial and venous markers expression in HuVECs-E4orf1-GFP and HuAECsE4orf1-GFP for different generations. ${ }^{*} P<0.05$, ${ }^{*} P<0.01$, ${ }^{* *} P<0.001$; $n=3$; Scale bar: $200 \mu \mathrm{m}$.

Additional file 2: Supplementary Fig. 2. Contrasting the effect of HuAECs-E4orf1-GFP and hFLSECs-E4orf1-GFP on CD34 ${ }^{+}$hCB cell expansion. (A) TNC expansion at day 14. (B) The cumulative curve of TNC in ex vivo expansion. (C) $\mathrm{CD} 34^{+} \mathrm{CD} 38^{-}$(left panel) and $\mathrm{CD} 34^{+} \mathrm{CD} 90^{+}$cell (right panel) expansion. (D) CFU number of amplified CD34 ${ }^{+}$hCB cells in HuAECs-E4orf1-GFP coculture or hFLSECs-E4orf1-GFP coculture. NS means 'no significant difference', ${ }^{*} P<0.05,{ }^{* *} \mathrm{P}<0.01 ; n=5$.
\end{abstract}

Additional file 3: Supplementary Fig. 3. Gene expression of PECs and expanded CD34 ${ }^{+}$hCB cells. (A) The morphology of PECs cultured in serum-free, cytokine-free condition. Scale bar: $200 \mu \mathrm{m}$. (B) qRT-PCR analysis of arterial and venous markers expression in primary HuVECs and HuAECs for different generations. (C) Comparison of the relative transcript levels of Notch ligands and receptors in expanded CD34 ${ }^{+}$hCB cells from different groups at day 14. (D) The transcript levels of Notch target genes (GATA2, HES1 and RUNX1) in expanded CD34 ${ }^{+}$hCB cells at day 14. NS means 'no significant difference', ${ }^{*} \mathrm{P}<0.05,{ }^{*} \mathrm{P}<0.01$, ${ }^{* * *} \mathrm{P}<0.001 ; n=3$.

Additional file 4: Supplementary Fig. 4. Multilineage engraftment measurements following transplantation. (A) Multilineage human hematopoietic cell engraftment after 16-week transplantation. (B) Percentage of engrafted human CD45 ${ }^{+}$hematopoietic cells at 4, 8 and 16 weeks after transplantation. $n=8$.

\section{Abbreviations}

CB: Cord blood; HSC: Hematopoietic stem cell; HSPCs: Hematopoietic stem and progenitor cells; HuAECs-E4orf1-GFP: Engineered human umbilical arterial endothelial cell; HuVECs: Human umbilical vein endothelial cells; HSCs: Hematopoietic stem cells; PSC: Pluripotent stem cells; iPSC: Induced pluripotent stem cells; ESC: Embryonic stem cells; BM: Bone marrow; UCB: Umbilical cord blood; MPB: Mobilized peripheral blood; ECs: Endothelial cells; AGM: Aorta-gonad-mesonephros; AECs: Arterial endothelial cells; HUAEC: Human umbilical arterial endothelial cell; GFP: Green fluorescent protein; PECs: Primary endothelial cells; NSG: NOD.Cg-Prkdc $c^{\text {scid }} / 12 \mathrm{rg}^{\mathrm{tm} 1 \mathrm{Wjl} / \mathrm{Sz}}$; PBS: Phosphate buffer saline; HuVECs-E4orf1-GFP: Engineered human umbilical vein endothelial cells; FACS: Fluorescence-activated cell sorting; VWF: von Willebrand Factor; qRT-PCR: Quantitative real-time polymerase chain reaction; CpE: Compound E; CFU: Colony-forming unit; CFU-E: CFUerythrocyte; BFU-E: Burst-forming unit-erythroid; CFU-G: CFU-granulocyte; CFU-GM: CFU-granulocyte, macrophage; CFU-M: CFU-megakaryocyte; CFCs: Colony-forming cells; IACUC: Institutional Animal Care and Use Committee; PB: Peripheral blood; TNCs: Total nucleated cells; hFLSECs: Human fetal liver; HE: Hemogenic endothelium

\section{Acknowledgments}

Thanks to Teacher Liliang Pei for his full support during this work.

\section{Authors' contributions}

$\mathrm{HL}$ performed the research and analyzed the data. HP designed and performed the research and wrote the manuscript. SW, $Y L, Z Y, L X$, and $Y H$ performed the animal experiments. XX, YJ, BZ, ZF, YB, LC, LH, and XN contributed new reagents or analytic tools. WY financial support and final approval of manuscript. XP financial support and final approval of manuscript. The authors read and approved the final manuscript.

\section{Funding}

This work was supported by grants from the National Key Research and Development Program of China (No. 2017YFA0103100; No. 2017YFA0103103; No. 2017YFA0103104), Guangzhou Health Care and Cooperative Innovation 
Major Project No. 201803040005, Nature Science Foundation of China (No. 81800103; No. 81872553), and Science and Technology Program of Guangzhou (No. 201604020007).

\section{Availability of data and materials}

Not applicable

\section{Ethics approval and consent to participate}

All procedures involving animals were approved by IACUC at Institute of Health Service and Transfusion Medicine (Reference number: IACUC of AMMS-13-2016-016). The ethical committee of Beijing Yuhe Chinese and Western Medicine Integrative Rehabilitation Hospital approved CB sample collection for the laboratory studies (ZXYEC-KT-2017-04-P01).

\section{Consent for publication}

Not applicable

\section{Competing interests}

The authors declare no conflict of interest.

\section{Author details}

'Stem Cell and Regenerative Medicine Lab, Institute of Health Service and Transfusion Medicine, Beijing 100850, China. ${ }^{2}$ Experimental Hematology and Biochemistry Lab, Beijing Institute of Radiation Medicine, Beijing 100850, China. ${ }^{3}$ South China Research Center for Stem Cell \& Regenerative Medicine, SCIB, Guangzhou 510005, China.

Received: 17 April 2020 Revised: 22 July 2020

\section{Accepted: 6 August 2020 Published online: 14 August 2020}

\section{References}

1. Bari S, Seah KK, Poon Z, Cheung AM, Fan X, Ong SY, Li S, Koh LP, Hwang WY. Expansion and homing of umbilical cord blood hematopoietic stem and progenitor cells for clinical transplantation. Biol Blood Marrow Transplant. 2015;21:1008-19.

2. Lee JH, Lee JB, Shapovalova Z, Fiebig-Comyn A, Mitchell RR, Laronde S, Szabo E, Benoit YD, Bhatia M. Somatic transcriptome priming gates lineagespecific differentiation potential of human-induced pluripotent stem cell states. Nat Commun. 2014;5:5605.

3. Lim WF, Inoue-Yokoo T, Tan KS, Lai MI, Sugiyama D. Hematopoietic cell differentiation from embryonic and induced pluripotent stem cells. Stem Cell Res Ther. 2013;4:71.

4. Wang $M$, Wang H, Wen Y, Chen X, Liu X, Gao J, Su P, Xu Y, Zhou W, Shi L, et al. MEIS2 regulates endothelial to hematopoietic transition of human embryonic stem cells by targeting TAL1. Stem Cell Res Ther. 2018;9:340.

5. Bone JM, Amara AB, Shenkin A, Hammad A, Sells RA, Alexander JL, McArdle F, Rustom R. Calcineurin inhibitors and proximal renal tubular injury in renal transplant patients with proteinuria and chronic allograft nephropathy. Transplantation. 2005;79:119-22.

6. Ballen KK, Gluckman E, Broxmeyer HE. Umbilical cord blood transplantation: the first 25 years and beyond. Blood. 2013;122:491-8.

7. Liao J, Sylla G, He Y, Leung W, Liu X, Chen J, Peng Z, Pei F, Li N, Ren Y, et al. Successful engraftment determined by the quality rather than quantity of the haematopoietic graft: a lesson from co-transplantation of unrelated cord blood and mobilized haploidentical peripheral blood in monozygotic twins. Br J Haematol. 2017;179:677-9.

8. Wagner JE, Broxmeyer HE, Byrd RL, Zehnbauer B, Schmeckpeper B, Shah N, Griffin C, Emanuel PD, Zuckerman KS, Cooper S, et al. Transplantation of umbilical cord blood after myeloablative therapy: analysis of engraftment. Blood. 1992;79:1874-81.

9. Ramalingam P, Poulos MG, Butler JM. Regulation of the hematopoietic stem cell lifecycle by the endothelial niche. Curr Opin Hematol. 2017;24:289-99.

10. Gordon-Keylock S, Sobiesiak M, Rybtsov S, Moore K, Medvinsky A. Mouse extraembryonic arterial vessels harbor precursors capable of maturing into definitive HSCs. Blood. 2013;122:2338-45.

11. Xue Y, Lv J, Zhang C, Wang L, Ma D, Liu F. The vascular niche regulates hematopoietic stem and progenitor cell lodgment and expansion via klf6accl25b. Dev Cell. 2017;42:349-62 e344.

12. Zhou F, Li X, Wang W, Zhu P, Zhou J, He W, Ding M, Xiong F, Zheng X, Li Z, et al. Tracing haematopoietic stem cell formation at single-cell resolution. Nature. 2016;533:487-92.
13. Yzaguirre AD, Speck NA. Extravascular endothelial and hematopoietic islands form through multiple pathways in midgestation mouse embryos. Dev Biol. 2016;415:111-21.

14. Ganuza M, Hadland B, Chabot A, Li C, Kang G, Bernstein I, McKinneyFreeman S. Murine hemogenic endothelial precursors display heterogeneous hematopoietic potential ex vivo. Exp Hematol. 2017:51:2535 e26.

15. Nagasawa T. Microenvironmental niches in the bone marrow required for B-cell development. Nat Rev Immunol. 2006;6:107-16.

16. Itkin T, Gur-Cohen S, Spencer JA, Schajnovitz A, Ramasamy SK, Kusumbe AP, Ledergor G, Jung Y, Milo I, Poulos MG, et al. Distinct bone marrow blood vessels differentially regulate haematopoiesis. Nature. 2016;532: 323-8.

17. Lu Y, Qian L, Zhang Q, Chen B, Gui L, Huang D, Chen G, Chen L. Palmitate induces apoptosis in mouse aortic endothelial cells and endothelial dysfunction in mice fed high-calorie and high-cholesterol diets. Life Sci. 2013;92:1165-73.

18. Aranguren XL, Agirre X, Beerens M, Coppiello G, Uriz M, Vandersmissen I, Benkheil M, Panadero J, Aguado N, Pascual-Montano A, et al. Unraveling a novel transcription factor code determining the human arterial-specific endothelial cell signature. Blood. 2013;122:3982-92.

19. Seandel M, Butler JM, Kobayashi H, Hooper AT, White IA, Zhang F, Vertes EL, Kobayashi M, Zhang Y, Shmelkov SV, et al. Generation of a functional and durable vascular niche by the adenoviral E4ORF1 gene. Proc Natl Acad Sci U S A. 2008;105:19288-93.

20. Butler JM, Gars EJ, James DJ, Nolan DJ, Scandura JM, Rafii S. Development of a vascular niche platform for expansion of repopulating human cord blood stem and progenitor cells. Blood. 2012;120:1344-7.

21. Wang D, Jie Q, Liu B, Li Y, Dai L, Luo J, Hou L, Wei Y. Saponin extract from Panax notoginseng promotesangiogenesis through AMPK and eNOSdependent pathways in HUVECS. Mol Med Rep. 2017;16:5211-8.

22. Jaffe EA, Nachman RL, Becker CG, Minick CR. Culture of human endothelial cells derived from umbilical veins. Identification by morphologic and immunologic criteria. J Clin Invest. 1973;52:2745-56.

23. Liu X, Qi J, Xu X, Zeisberg M, Guan K, Zeisberg EM. Differentiation of functional endothelial cells from human induced pluripotent stem cells: a novel, highly efficient and cost effective method. Differentiation. 2016;92: $225-36$.

24. Zhang J, Chu LF, Hou Z, Schwartz MP, Hacker T, Vickerman V, Swanson S, Leng $\mathrm{N}$, Nguyen BK, Elwell A, et al. Functional characterization of human pluripotent stem cell-derived arterial endothelial cells. Proc Natl Acad Sci U S A. 2017:114:E6072-8.

25. Eichmann A, Yuan L, Moyon D, Lenoble F, Pardanaud L, Breant C. Vascular development: from precursor cells to branched arterial and venous networks. Int J Dev Biol. 2005:49:259-67.

26. Morrow D, Hatch E, Hamm K, Cahill PA, Redmond EM. Flk-1/KDR mediates ethanol-stimulated endothelial cell Notch signaling and angiogenic activity. J Vasc Res. 2014;51:315-24.

27. Barbato JE, Tzeng E. Nitric oxide and arterial disease. J Vasc Surg. 2004;40: 187-93.

28. Gurlek A, Esenboga K, Ozcan OU, OF C, Aribal Ayral P, Ozelci Kavas G, Erol C. Serum nitric oxide levels in patients with coronary artery ectasia. Anatol J Cardiol. 2016:16:947-52.

29. Blank U, Ehrnstrom B, Heinz N, Nilsson E, Brun A, Baum C, Schiedlmeier B, Karlsson S. Angpt/4 maintains in vivo repopulation capacity of CD34+ human cord blood cells. Eur J Haematol. 2012;89:198-205.

30. Zhang CC, Lodish HF. Insulin-like growth factor 2 expressed in a novel fetal liver cell population is a growth factor for hematopoietic stem cells. Blood. 2004:103:2513-21.

31. Chen T, Zhang P, Fan W, Qian F, Pei L, Xu S, Zou Z, Ni B, Zhang Y. Cotransplantation with mesenchymal stem cells expressing a SDF-1/HOXB4 fusion protein markedly improves hematopoietic stem cell engraftment and hematogenesis in irradiated mice. Am J Transl Res. 2014;6:691-702.

32. Shutter JR, Scully S, Fan W, Richards WG, Kitajewski J, Deblandre GA, Kintner CR, Stark KL. DII4, a novel Notch ligand expressed in arterial endothelium. Genes Dev. 2000;14:1313-8.

33. Moore KA, Ema H, Lemischka IR. In vitro maintenance of highly purified, transplantable hematopoietic stem cells. Blood. 1997;89:4337-47.

34. Sandler VM, Lis R, Liu Y, Kedem A, James D, Elemento O, Butler JM, Scandura JM, Rafii S. Reprogramming human endothelial cells to haematopoietic cells requires vascular induction. Nature. 2014;511:312-8. 
35. Benedito R, Trindade A, Hirashima M, Henrique D, da Costa LL, Rossant J, Gill PS, Duarte A. Loss of Notch signalling induced by DIl4 causes arterial calibre reduction by increasing endothelial cell response to angiogenic stimuli. BMC Dev Biol. 2008:8:117.

36. Yamamizu K, Matsunaga T, Uosaki H, Fukushima H, Katayama S, HiraokaKanie M, Mitani K, Yamashita JK. Convergence of Notch and beta-catenin signaling induces arterial fate in vascular progenitors. J Cell Biol. 2010;189: 325-38.

37. Rocha SF, Adams RH. Molecular differentiation and specialization of vascular beds. Angiogenesis. 2009;12:139-47.

38. de Lima M, McNiece I, Robinson SN, Munsell M, Eapen M, Horowitz M, Alousi A, Saliba R, McMannis JD, Kaur I, et al. Cord-blood engraftment with ex vivo mesenchymal-cell coculture. N Engl J Med. 2012;367:2305-15.

39. Michalicka M, Boisjoli G, Jahan S, Hovey O, Doxtator E, Abu-Khader A, Pasha R, Pineault N. Human bone marrow mesenchymal stromal cell-derived osteoblasts promote the expansion of hematopoietic progenitors through Beta-catenin and notch signaling pathways. Stem Cells Dev. 2017;26:1735-48.

40. Yong KS, Keng CT, Tan SQ, Loh E, Chang KT, Tan TC, Hong W, Chen Q. Human CD34(lo)CD133(lo) fetal liver cells support the expansion of human CD34(hi)CD133(hi) hematopoietic stem cells. Cell Mol Immunol. 2016;13:605-14.

41. Ding L, Saunders TL, Enikolopov G, Morrison SJ. Endothelial and perivascular cells maintain haematopoietic stem cells. Nature. 2012;481:457-62.

42. Kumar ME, Bogard PE, Espinoza FH, Menke DB, Kingsley DM, Krasnow MA. Mesenchymal cells. Defining a mesenchymal progenitor niche at single-cell resolution. Science. 2014;346:1258810.

43. Greenbaum A, Hsu YM, Day RB, Schuettpelz LG, Christopher MJ, Borgerding JN, Nagasawa T, Link DC. CXCL12 in early mesenchymal progenitors is required for haematopoietic stem-cell maintenance. Nature. 2013:495:227-30.

44. Raynaud CM, Butler JM, Halabi NM, Ahmad FS, Ahmed B, Rafii S, Rafii A. Endothelial cells provide a niche for placental hematopoietic stem/ progenitor cell expansion through broad transcriptomic modification. Stem Cell Res. 2013;11:1074-90.

45. Gori JL, Butler JM, Kunar B, Poulos MG, Ginsberg M, Nolan DJ, Norgaard ZK, Adair JE, Rafii S, Kiem HP. Endothelial cells promote expansion of long-term engrafting marrow hematopoietic stem and progenitor cells in primates. Stem Cells Transl Med. 2017;6:864-76.

46. Li H, Pei H, Xie X, Wang S, Jia Y, Zhang B, Fan Z, Liu Y, Bai Y, Han Y, et al. Liver sinusoidal endothelial cells promote the expansion of human cord blood hematopoietic stem and progenitor cells. Int J Mol Sci. 2019;20(8): 1985.

47. Chagraoui J, Lepage-Noll A, Anjo A, Uzan G, Charbord P. Fetal liver stroma consists of cells in epithelial-to-mesenchymal transition. Blood. 2003;101: 2973-82.

48. Krebs LT, Shutter JR, Tanigaki K, Honjo T, Stark KL, Gridley T. Haploinsufficient lethality and formation of arteriovenous malformations in Notch pathway mutants. Genes Dev. 2004;18:2469-73.

49. Krebs LT, Xue Y, Norton CR, Shutter JR, Maguire M, Sundberg JP, Gallahan D, Closson V, Kitajewski J, Callahan R, et al. Notch signaling is essential for vascular morphogenesis in mice. Genes Dev. 2000;14:1343-52.

50. Sorensen I, Adams RH, Gossler A. DLL1-mediated Notch activation regulates endothelial identity in mouse fetal arteries. Blood. 2009:113:5680-8.

51. Swift MR, Weinstein BM. Arterial-venous specification during development. Circ Res. 2009;104:576-88.

52. Ayllon V, Bueno C, Ramos-Mejia V, Navarro-Montero O, Prieto C, Real PJ, Romero T, Garcia-Leon MJ, Toribio ML, Bigas A, et al. The Notch ligand DLL4 specifically marks human hematoendothelial progenitors and regulates their hematopoietic fate. Leukemia. 2015;29:1741-53.

53. Corada M, Nyqvist D, Orsenigo F, Caprini A, Giampietro C, Taketo MM, Iruela-Arispe ML, Adams RH, Dejana E. The Wnt/beta-catenin pathway modulates vascular remodeling and specification by upregulating DIl4/ Notch signaling. Dev Cell. 2010;18:938-49.

54. Kim PG, Albacker CE, Lu YF, Jang IH, Lim Y, Heffner GC, Arora N, Bowman TV, Lin MI, Lensch MW, et al. Signaling axis involving Hedgehog, Notch, and $\mathrm{Scl}$ promotes the embryonic endothelial-to-hematopoietic transition. Proc Natl Acad Sci U S A. 2013;110:E141-50.

55. Boisset JC, van Cappellen W, Andrieu-Soler C, Galjart N, Dzierzak E, Robin C. In vivo imaging of haematopoietic cells emerging from the mouse aortic endothelium. Nature. 2010:464:116-20.

56. Tian DM, Liang L, Zhao XC, Zheng MH, Cao XL, Qin HY, Wang CM, Liang YM, Han H. Endothelium-targeted Delta-like 1 promotes hematopoietic stem cell expansion ex vivo and engraftment in hematopoietic tissues in vivo. Stem Cell Res. 2013;11:693-706.

\section{Publisher's Note}

Springer Nature remains neutral with regard to jurisdictional claims in published maps and institutional affiliations.
Ready to submit your research? Choose BMC and benefit from:

- fast, convenient online submission

- thorough peer review by experienced researchers in your field

- rapid publication on acceptance

- support for research data, including large and complex data types

- gold Open Access which fosters wider collaboration and increased citations

- maximum visibility for your research: over $100 \mathrm{M}$ website views per year

At $\mathrm{BMC}$, research is always in progress.

Learn more biomedcentral.com/submissions 